\title{
Evaluation of Knowledge Management Maturity
}

\author{
Hossein Amoozad Khalili, Anahita Maleki, Azita Sherej Sharifi, Mohamad Hasan Salmani, and Somaye \\ Rahnama Farshami
}

\begin{abstract}
Confronting fierce global competition, organizations have implemented knowledge management to enhance competitive advantages. With increasing investments in resources for knowledge management implementation in many organizations, measuring knowledge management maturity has become an important agenda among researchers and practitioners. This study develops a knowledge navigator model (KNMTM) to navigate knowledge management (KM) implementation journey. The KNM comprises two frameworks: evaluation and calculation framework .
\end{abstract}

Index Terms-Knowledge management; maturity; knowledge navigator model.

\section{INTRODUCTION}

In order to gain and sustain a competitive advantage in the global economy, today's organizations need to effectively mobilize their knowledge resources.

Knowledge management consists of a special systematic and organizational process in which one is allowed to acquire, organize, maintain, apply, distribute, publish and recreate both explicit and implicit knowledge for the staff to promote the organizational performance and value creation.

Knowledge management maturity, the level of capabilities that exist in an organization with their different dimensions influence the knowledge management process. Every organization, as judged by functions it has performed on knowledge management is at a certain level of maturity that shows its status quo on knowledge management. KMMM (knowledge management maturity model) in an organization describes some steps of growth that can be expected by the organization to reach its knowledge management development. One maturity model is made up of some maturation levels that can be obtained step by step by an organization over a period of time [1].

However, in current KM maturity models, there is a lack of an evaluation framework with detailed items and procedures which could be easily obtained and fully understood by practitioners and researchers. This study develops a

Manuscript received July 03, 2012; revised September 10, 2012.

Hossein Amoozad Khalili is with the Industrial Engineering Department, Islamic Azad University Nowshahr Branch, Nowshahr, Mazandaran, Iran (e-mail: Amoozad_ie@iauns.ac.ir).

Anahita Maleki is with the Industrial Engineering Department, Iran University of Science and Technology, Tehran, Iran (e-mail: Anahitamaleki@yahoo.com).

Azita Sherej Sharifi is with the Management and accounting Department, Islamic Azad University, Nowshahr Branch, Nowshahr, Mazandaran, Iran (e-mail: Sharifi@iauns.ac.ir).

Mohamad Hasan Salmani and Somaye Rahnama Farshami are with the Industrial Engineering Department, Payamnur University, Tehran Center Branch, Tehran, Iran (e-mail: Mohammad_Salmani_92@yahoo.com; Rahnamas@yahoo.com). comprehensive framework which we call Knowledge Navigator Model (KNM).

\section{ThE KM MATURITY MODELS}

A review of the literature on this subject matter identified a wide range of models on knowledge management maturity. Typically 5 out of 8 levels of knowledge management maturity have been defined as "no knowledge management maturity"' as compared with those of ideal where knowledge management tend to be an organizational function. Conceptually management maturity models can be categorized as groups. This is done based on a capability maturity model (CMM) provided by software engineering institute/Carnegie Mellon (SEI) to insure whether they can be created. This CMM was earnestly introduced by SEI during 1990s and during this period of time some representations of this model were undertaken by SEI. CMM is a model that provides a roadmap to implement progressive changes on different organizational processes. It is a foundational model that is used to measure the level of organizations' maturity in particular those with intensive knowledge processes such as software producing organizations [2].

KPMG defines the four key areas of $\mathrm{KM}$ as people, process, content and technology. In each area there are certain activities to be done. Firms can be assessed according to how they implement these activities [3]. This model is often used for benchmarking purposes. On the basis of an assessment of the organization's activities, the firm is placed in a five-level model called the "Knowledge Journey," The model starts form knowledge chaotic level and progresses to knowledge aware, knowledge focused, knowledge managed, and knowledge centric level.

Siemens' KMMM is a structured method for assessing an organization's overall position in KM. KMMM consists of an analysis model, a development model and a defined assessment process [4]. The analysis model helps the KMMM consultant to take account of all important aspects of KM and reveals which key areas and topics should be developed in the future. The development model provides information as to how the respective key areas and topics can be best developed to reach the next maturity level. The assessment process structures all relevant steps from assessment definition to result interpretation. This deliberately designed model allows both, qualitative and quantitative outputs on the current status of $\mathrm{KM}$ in an organization. The development model defines five maturity levels of KM: 1 . initial, 2. repeated, 3. defined, 4. managed, and 5. optimizing.

Lee and Kim have developed an integrated management framework for building the organizational capabilities of KM. 
The framework consists of four major management components: organizational knowledge, knowledge workers, $\mathrm{KM}$ processes, and information technology. Based on this framework, they propose a stage model of organizational KM encompassing initiation, propagation, integration, and networking stages. Each of the four stages is differentiated in terms of its management goals, activities, and characteristics of the management components [5].

\section{TARget MAnAgEMENT OBJECTS IN KM}

As candidates of 'something' to be managed, various components have been identified in the KM literature. The most commonly mentioned components are knowledge itself, the $\mathrm{KM}$ process, knowledge workers, trust-based human relationship, information technologies, knowledge-oriented Culture, flexible organizational structure, performance measures and rewards, strategy, leadership [6, 7].

However, considering all of them as target management objects will be difficult since some of them are not only too broad or vague but also too complex to manage. Therefore, we propose that strategy, the KM processes, information technologies, Human resource and organizational culture should be emphasized and managed as the determinants of KM implementation effectiveness.

\section{A. Strategy}

To be successful, a KM strategy must do more than just outline high-level goals such as 'become a knowledge-enabled organization'.

We focus strongly on the needs analysis activities with staff, to drive a primarily bottom-up strategy, as follows:

1. Identify the key staff groups within the organization. These groups deliver the greatest business value, or are involved in the most important business activities.

2. Conduct comprehensive and holistic needs analysis activities with selected staff groups, to identify key needs and issues.

3. Supplement this research with input from senior management and organizational strategy documents, to determine an overall strategic focus.

4. Based on these findings, develop recommendations for addressing the issues and needs identified.

5. Implement a series of strategic and tactical initiatives, based on the recommendations. These will select suitable knowledge management techniques and approaches.

The main steps of strategy are Knowledge management strategy, Knowledge management vision, Knowledge management goals.

\section{B. KM Process}

KM processes can be thought of as a structured coordination for managing knowledge effectively. KM processes are broad processes that help in discovering, capturing, sharing, and applying knowledge. Knowledge discovery may be defined as the development of new tacit or explicit knowledge from data and information or from the synthesis of prior knowledge [8]. Knowledge capture is the process of retrieving either explicit or tacit knowledge that resides within people, artifacts, or organizational entities. Knowledge sharing is the process through which explicit or tacit knowledge is communicated to other individuals. Knowledge application is the process through which some individuals utilize knowledge possessed by other individuals without actually acquiring, or learning, that knowledge.

\section{Information Technology}

The IT infrastructure includes data processing, storage, communication technologies and systems, and management information. The effectiveness and efficiency of the IT infrastructure supporting the $\mathrm{KM}$ implementation is an essential condition at the initial stage and across the KM maturity stages. One possible way of systematically viewing the IT infrastructure is to consider the capabilities it provides in four aspects: reach, depth, richness, and aggregation [9]. As organizations work to develop and improve their KMS, it will also change from a closed system, such as a GroupWare, or workflow system, to an enterprise-wide knowledge sharing system with more intelligent technologies and, finally, to a global sharing system. Gottschalk suggests four stages of growth for KM technology. Stage I is labeled “"end-user-tool systems” or " "person-to-technology," as IT provides people with tools that improve personal efficiency. Examples are word processing, spreadsheets, and presentation software. Stage II is labeled "who-knows-what systems" or "person-to-person," as people use IT to find other knowledge workers. Examples are yellow-page systems, and intranets. Stage III is labeled "what-they-know systems” or "person-to-information," as IT provides people with access to information that is typically stored in documents. Examples include data mining, and search engines. Stage IV is labeled "how they-think systems" or "person-to-system," in which the system is intended to help solve a knowledge problem. Examples are expert systems, artificial intelligence, and business intelligence.

Hence, the IT trigger for KM, the focus when applying IT, the dominating strategy for KMT, and the attitude towards IT change according to the KM stages [10].

\section{Human Resource}

Knowledge management and human resources management initiatives are focused on harnessing the available knowledge assets and to prevent knowledge from walking out of the door. Hence, there is a need for the integration between the knowledge management initiatives and the HR policies of the organization.

Regard and motivation systems, Training of personnel, Cooperation of personnel, and Protection of personnel, strengthening of personnel are the indicator of human resources.

\section{E. Organizational Culture}

Culture incorporates a set of shared values, norms and beliefs, mainly implicit, that the members of an organization possess. Some people find a positive relationship between organizational culture (defined by collaboration, trust, and learning) and knowledge creation processes and conclude that shaping an organization's cultural factors is key to the ability of the firm to manage knowledge effectively. Therefore, organizations should seek to promote and build the types of cultural values that support their specific KM objectives.

The certain types of organizational values will lead to 
different types of KM behavior and that these behaviors will lead to varying outcomes. Thus, "good” cultural values such as sharing, openness, and trust will lead to positive KM behaviors, which will lead to innovation and efficiency, whereas "bad" values will lead to dysfunctional KM behaviors and, hence, undesirable outcomes such as inefficiency.

Therefore, an organization's culture should provide support and incentives as well as encourage knowledge-related activities by creating environments for knowledge exchange and accessibility [11].

\section{The Proposed Knowledge Navigator Model}

The KNM comprises two frameworks: evaluation and calculation framework. The main task of evaluation process is to collect users' preferences for evaluation items, while the calculation process is to count the evaluation scores and obtain the KM maturity level.

\section{A. Evaluation Framework}

Step 1: The KM maturity level can be defined as five stages: knowledge chaotic stage, knowledge conscientious stage, KM stage, KM advanced stage, and KM integration stage.

Step 2: The evaluation framework for KNM consists of three aspects: five target management objects, $34 \mathrm{KM}$ activities, and 7 key areas. The five target management objects, including strategy, KM Process, IT, Human resource and organization culture. The $34 \mathrm{KM}$ activities are those activities or practices that directly or indirectly promote KM implementation. Each KM activity belongs to a corresponding target management object, a maturity level, and a key area (Table I).

TABLE I: THE CORRESPONDING TARGET MANAGEMENT OBJECT, MATURITY LEVEL, AND KA FOR EACH KM ACTIVITY

\begin{tabular}{|c|c|}
\hline Key Area & KM Activity \\
\hline KM strategy & $\begin{array}{l}\text { 1. Business vision, mission and task } \\
\text { 2. KM strategy } \\
\text { 3. The processes or regulations to continually } \\
\text { improve KM strategy } \\
\text { 4. The link between business vision, mission } \\
\text { and task, and KM strategy }\end{array}$ \\
\hline KM assessment & $\begin{array}{l}\text { 1. The use of quantitative measures and the } \\
\text { concept of quality control to assess KM } \\
\text { activities } \\
\text { 2. KM assessment methods link to the } \\
\text { organization performance management } \\
\text { 3. The overall benefit from KM in terms of the } \\
\text { improvement on the customer service, the } \\
\text { product, and the partner relations, and thus } \\
\text { obtain good reputation } \\
\text { 4. Consider the expense of implementing KM } \\
\text { activities in annual budget } \\
\text { 5. The related decision making process will } \\
\text { consider the investment return rate of KM }\end{array}$ \\
\hline $\begin{array}{l}\quad \text { Knowledge } \\
\text { identify and } \\
\text { classification }\end{array}$ & $\begin{array}{l}\text { 1. Members' identification of the knowledge } \\
\text { which members are related with } \\
\text { 2. Members' identification of the knowledge } \\
\text { within the organization } \\
\text { 3. Members' classification of the } \\
\text { organizational knowledge } \\
\text { 4. Perform the knowledge audit }\end{array}$ \\
\hline Knowledge & 1. Members have the culture of knowledge \\
\hline
\end{tabular}

\begin{tabular}{|c|c|}
\hline sharing & $\begin{array}{l}\text { sharing, and with the positive attitude } \\
\text { 2. The regulations or processes to facilitate } \\
\text { knowledge sharing, } \\
\text { 3. The regulations or processes to encourage } \\
\text { employees to participate projects and share the } \\
\text { project results } \\
\text { 4. The regulations or processes to share } \\
\text { knowledge with external organizations }\end{array}$ \\
\hline $\begin{array}{l}\text { Knowledge } \\
\text { application }\end{array}$ & $\begin{array}{l}\text { 1. Members are able to apply internal } \\
\text { knowledge to accomplish task } \\
\text { 2. Members are able to apply external } \\
\text { knowledge to accomplish task }\end{array}$ \\
\hline $\begin{array}{c}I T \\
\text { infrastructure }\end{array}$ & $\begin{array}{l}\text { 1. Members are able to use e-mail, internet or } \\
\text { search engine } \\
\text { 2. The integral information system to transfer } \\
\text { and deposit information } \\
\text { 3. The database is updated periodically and the } \\
\text { content of the database are consistent } \\
\text { 4. Data warehouse }\end{array}$ \\
\hline KM system & $\begin{array}{l}\text { 1 The regulations or processes to construct and } \\
\text { maintain Yellow Page } \\
\text { 2. The regulations or processes to construct and } \\
\text { maintain knowledge map } \\
\text { 3. Provide knowledge base system } \\
\text { 4. The regulations or processes to acquire } \\
\text { internal knowledge to improve the quality and } \\
\text { quantity of knowledge in Knowledge Base } \\
\text { 5. The regulations or processes to acquire } \\
\text { external knowledge to improve the quality and } \\
\text { quantity of knowledge in Knowledge Base } \\
\text { 6. Provides the system function of sharing tacit } \\
\text { knowledge } \\
\text { 7. Provides the system function of supporting } \\
\text { individual and group KM } \\
\text { 8. System connect to daily work _. } \\
\text { 9. System connect to other enterprise system } \\
\text { 10. Provide system function to share } \\
\text { tacit/explicit knowledge with external } \\
\text { organizations_- } \\
\text { 11. Use data mining, text mining or other } \\
\text { artificial intelligence technology to acquire } \\
\text { business intelligence }\end{array}$ \\
\hline
\end{tabular}

\section{B. Calculation Framework}

There are four steps in the calculation process:

Step 1. Count the sum of evaluation items for each target management object to obtain the evaluation scores of five target management objects

Step 2. Compare the score of each target management object with the score ranges to decide the maturity level of each target management object

Step 3. Count the evaluation score of combined target management object (combine the scores of three target management objects into one overall score)

Step 4. Compare the score of combined target management object with the score ranges to obtain the maturity level of combined target management object.

\section{CONCLUSION AND FINDINGS}

The implementation of Knowledge Management represents an important change in the process, substructure and culture of an organization which evolve over a time frame.

Various factors influence knowledge management success and more attention to the technology alone cannot benefit the organization from the possible gains of a well designed knowledge management systems. Therefore it is recommended that the organization pay attention to all influential factors. The influential factors in the knowledge 
management process are directly related to the various levels of progression. The information in this article can include some parts knowledge management profile to encourage the organizational participant to optimize knowledge management and decision making.

\section{REFERENCES}

[1] N. Khatibian, T. Hasan Gholi Pour, and H. Abedi Jafari, "Measurement of knowledge management maturity level within organizations," Business Strategy Series, vol. 11. no.1, pp.54-70, 2010.

[2] B. Curtis, W.E. Hefley, and S. A. Miller, "People Capability Maturity Model (P-CMM) - Version 2.0”, Software Engineering Institute (SEI) - Carnegie Mellon University, Pittsburgh, PA, pp. 3-59, 2001.

[3] KPMG Consulting. "Knowledge management research report 2000" [Online]. Available: http://www.kpmg.co.uk, 2000.

[4] Siemens. "Knowledge management maturity model (KMMM)" [Online]. Available: http://www.siemens.com), 2004.

[5] J. Lee and Y. Kim, "A stage model of organizational knowledge management: A latent content analysis,” Expert Systems with Application, vol. 20, no. 4, pp. 299-311, 2001.
[6] T. S. Raghu and A. Vinze, “A business process context for knowledge management,” Decision Support Systems, vol. 43, no. 4, pp. 1062-1079, 2007.

[7] E. Bertino, L. R. Khan, R. Sandhu, and B. Thuraisingham, "Secure knowledge management: Confidentiality, trust, and privacy,” IEEE Transactions on Systems, MAN, and Cybernetics - Part A: Systems and Humans, vol. 36, no. 3, pp. 429-438, 2006.

[8] D. L. Paul, "Collaborative activities in virtual settings: A knowledge management perspective of telemedicine," Journal of Management Information Systems, vol. 22, no. 4, pp.143-176, 2006.

[9] P. Evans and T. S. Wurster, "Getting real about virtual commerce," Harvard Business Review, vol. 77, no. 6, pp. 85-94, 1999.

[10] P. Gottschalk, "Expert systems at stage IV of the knowledge management technology stage model: The case of police investigations,” Expert Systems with Applications, vol. 31, no. 3, pp. 617-628, 2006.

[11] B. D. Janz and P. Prasarnphanich, "Understanding the antecedents of effective knowledge management: The importance of a knowledge-centered culture,” Decision Sciences, vol. 34, no. 2, pp. 351-384, 2003. 